\title{
Effect of $\alpha 2$-macroglobulin in the early stage of jaw osteoradionecrosis
}

\author{
JIE LI $^{1,2^{*}}$, PING YIN $^{1 *}$, XUEYING CHEN $^{1}$, XIANGBO KONG $^{3,4}$, WANZHEN ZHONG $^{1}$, YAPING GE ${ }^{1}$, \\ YANGYANG SHE ${ }^{1}$, XUEHONG XIAN $^{1}$, LEI QI $^{5}$, ZHI LIN $^{1}$, JUSTINE MOE $^{6}$ and SILIAN FANG ${ }^{1,7}$ \\ ${ }^{1}$ Department of Oral and Maxillofacial Surgery, The Sixth Affiliated Hospital of Sun Yat-sen University, Guangzhou, \\ Guangdong 510655; ${ }^{2}$ The Second Dental Clinic, Department of Oral Implantology, Ninth People's Hospital, \\ Shanghai Jiao Tong University, School of Medicine, National Clinical Research Center of Oral Diseases, Shanghai 201900; \\ ${ }^{3}$ Department of Stomatology, Sun Yat-sen Memorial Hospital of Sun Yat-sen University, Guangzhou, \\ Guangdong 510120, P.R. China; ${ }^{4}$ Visiting Scholar, Department of Periodontics and Oral Medicine, \\ University of Michigan School of Dentistry, Ann Arbor, MI 48109, USA; ${ }^{5}$ Department of Oral and \\ Cranio-maxillofacial Surgery, Ninth People's Hospital, Shanghai Jiao Tong University, School of Medicine, \\ National Clinical Research Center for Oral Diseases, Shanghai 200001, P.R. China; \\ ${ }^{6}$ Department of Oral and Maxillofacial Surgery, University of Michigan; \\ ${ }^{7}$ Visiting Scholar, Department of Oral and Maxillofacial Surgery, University of Michigan, Ann Arbor, MI 48109, USA
}

Received September 26, 2019; Accepted March 30, 2020

DOI: $10.3892 / \mathrm{ijo} .2020 .5051$

\begin{abstract}
Advanced osteoradionecrosis (ORN) is one of the most serious complications in patients with head and neck cancer, resulting in poor prognosis. Numerous studies have therefore focused on the pathogenesis and interventions of ORN early stage. The present study aimed to investigate whether $\alpha 2$-macroglobulin $(\alpha 2 \mathrm{M})$ could prevent early-stage jaw osteoradionecrosis caused by radiotherapy (RT). Following local injection of $\alpha 2 \mathrm{M}$, a single dose of $30 \mathrm{~Gy}$ was delivered to rats for pathological exploration. For 28 days, the irradiated mandible and soft tissues were examined for potential changes. Furthermore, primary human bone marrow
\end{abstract}

Correspondence to: Professor Silian Fang, Department of Oral and Maxillofacial Surgery, The Sixth Affiliated Hospital of Sun Yat-sen University, 26 Yuancun Erheng Road, Guangzhou, Guangdong 510655, P.R. China

E-mail: fangsilian@126.com

Dr Justine Moe, Section of Oral and Maxillofacial Surgery, Department of Surgery, University of Michigan, 1515 East Hospital Drive, Towsley Center, G1200, Ann Arbor, MI 48109, USA

E-mail: jusmoe@med.umich.edu

"Contributed equally

Abbreviations: 8-OHdG, 8-hydroxy-2'-deoxyguanosine; $\alpha 2 \mathrm{M}$, a2-macroglobulin; hBMMSCs, human bone marrow mesenchymal stem cells; HO-1, heme oxygenase-1; ORN, osteoradionecrosis; ROS, reactive oxygen species; RT, radiotherapy; SOD2, superoxide dismutase 2

Key words: a2-macroglobulin, jaw osteoradionecrosis, radioprotective effect, oxidative damage, antioxidant mesenchymal stem cells pretreated with $\alpha 2 \mathrm{M}$ followed by 8 Gy irradiation (IR) were also used. Tartrate-resistant acid phosphatase assay, terminal uridine deoxynucleotidyl nick end labeling assay and immunohistochemical staining were performed on irradiated mandibular bone, tongue or buccal mucosa tissues from rats. Cell proliferation was assessed by evaluating the cell morphology by microscopy and by using the cell counting kit-8. Fluorescence staining, flow cytometry and western blotting were conducted to detect the reactive oxygen species level, cell apoptosis and protein expression of superoxide dismutase 2 (SOD2), heme oxygenase-1 (HO-1) and phosphorylated Akt following irradiation. The results demonstrated that $\alpha 2 \mathrm{M}$ attenuated physical inflammation, osteoclasts number and fat vacuole accumulation in mandibular bone marrow and bone marrow cell apoptosis following IR in vivo. Furthermore, $\alpha 2 \mathrm{M}$ pretreatment suppressed the expression of 8-hydroxy-2'-deoxyguanosine in mandibular bone and tongue paraffin embedded sections, which is a marker of oxidative damage, and increased SOD2 expression in mucosa and tongue paraffin embedded sections. The present study demonstrated the efficient regulation of antioxidative enzymes, including SOD2 and heme oxygenase-1, and reduction in oxidative damage by $\alpha 2 \mathrm{M}$. In addition, in vitro results confirmed that $\alpha 2 \mathrm{M}$ may protect cells from apoptosis and suppress reactive oxygen species accumulation. Overall, the present study demonstrated that $\alpha 2 \mathrm{M}$ treatment may exert some radioprotective effects in early-stage ORN via antioxidant mechanisms, and may therefore be considered as a potential alternative molecule in clinical prophylactic treatments.

\section{Introduction}

Osteoradionecrosis (ORN) is the most dangerous adverse clinical complication in patients with head and neck cancer 
following treatment with radiotherapy (RT), with an incidence of $5-15 \%$ (1-4). Most patients with head and neck cancer receive radiation therapy (5). Marx (6) reported that ORN occurs following bone tissue hypoxia, hypocellularity and hypovascularity in the early stage; however, the underlying mechanisms remain unclear. In the last decades, studies demonstrated that radiation-induced fibrosis promotes the development of ORN $(7,8)$. Fibrosis is a common feature of end-stage ORN (9) and is rarely reversible. However, $\mathrm{Xu}$ et al (10) reported that reducing local blood flow and subsequent hypovascularity could lead to an imbalance in bone remodeling, suggesting that microvascular damage has a major impact on ORN early stage. However, whether IR directly causes bone cell death, triggers other factors that suppress bone cell function or results in a combination of both effects, remain unknown.

RT can induce the generation of high levels of reactive oxygen species (ROS), leading to microvascular structure necrosis, local ischemia and subsequent tissue loss (11). ROS overproduction also inhibits the survival of tissue-borne multipotent stromal cells in numerous tissues (12). In addition, Mazur et al (13) reported that irradiation (IR) can induce bone marrow cell apoptosis. Although the underlying mechanisms of radiation injury caused by ROS have been extensively studied, a valid medical therapy designed to prevent the deleterious side effects of radiation in patients is not currently available (14).

$\alpha 2$-macroglobulin $(\alpha 2 \mathrm{M})$ is an acute-phase protein that exerts radioprotective effects $(15,16)$. Pretreatment of rats by total-body irradiation with $\alpha 2 \mathrm{M}$ can significantly reduce radiation-induced DNA damage and completely restore liver function and body weight $(17,18)$. In addition, a previous study reported that the rat acute-phase $\alpha 2 \mathrm{M}$ protein serves a central role in amifostine-mediated radioprotection, increasing the protective effect by 45 -fold (19). As demonstrated in a study from our laboratory, $\alpha 2 \mathrm{M}$ maintains the osteogenic potential of human bone marrow mesenchymal stem cells (hBMMSCs) following IR (20). In particular, hBMMSCs are among the main cells damaged during bone tissue radiation $(21,22)$. Radiation can alter hBMMSC proliferation, induce genomic DNA damage and micronucleus formation and inhibit the osteogenic differentiation of hBMMSCs (23).

The radioprotective effect of $\alpha 2 \mathrm{M}$ in the late stage of ORN, with a notable effect on the fibrosis in bone marrow, has been demonstrated in our previous study (24). However, this treatment could not reverse the development of ORN disease process. The present study aimed therefore to examine whether $\alpha 2 \mathrm{M}$ could exert a radioprotective effect on early-stage ORN in vivo and in vitro, and to explore its underlying mechanisms.

\section{Materials and methods}

Establishment of the ORN animal model. A total of 72 Sprague-Dawley male rats (12-week old, 350 g) that were purchased from the Laboratory Animal Center of Sun Yat-sen University, were randomly assigned into four groups as follows: control group, $\alpha 2 \mathrm{M}$ group, RT group and $\alpha 2 \mathrm{M}+\mathrm{RT}$ group (n=18 animals per group). Following anesthesia with pentobarbital $(1 \% ; 50 \mathrm{mg} / \mathrm{kg}$, intraperitoneal injection), a subperiosteal injection of $0.5 \mathrm{ml}$ of $2 \mathrm{mg} / \mathrm{ml} \alpha 2 \mathrm{M}$ (cat. no. 441251-10MG; EMD Millipore) was prophylactically administered to mice from the $\alpha 2 \mathrm{M}$ and $\alpha 2 \mathrm{M}+\mathrm{RT}$ groups 30 min prior to IR, whereas the control and RT groups were injected with the same volume of physiological saline. Following preoperative anesthesia induction, a single dose of $30 \mathrm{~Gy}$ (voltage, $160 \mathrm{kV}$; current, $25 \mathrm{~mA}, 2.75 \mathrm{~Gy} / \mathrm{min}$, $10.91 \mathrm{~min}$; Rad Source Technologies, Inc.) was delivered to the left mandible of mice from the RT and $\alpha 2 \mathrm{M}+\mathrm{RT}$ groups. Improved 3D-printed mandible fixtures and a lead sheet were used to precisely deliver radiation to the mandible and protect the surrounding tissues by shielding them from IR. The dosage was based on an extensive review of the literature $(25,26)$ and previous work from our laboratory (20). All rats were fed a liquid diet during the first week after IR. The flow diagram for the experiment is shown in Fig. SI. Six rats in each group were sacrificed with pentobarbital $(1 \%, 120 \mathrm{mg} / \mathrm{kg}$, intraperitoneal injection) on day 7, 14 and 28 following IR. Death verification included cardiac arrest, respiratory arrest and disappearance of various reflexes. Unilateral mandible, tongue and buccal mucosal tissue were excised and examined immediately. In addition, humane endpoints included the following: 20-25\% body weight loss, complete loss of appetite for $24 \mathrm{~h}$ or loss of appetite $(<50 \%$ of normal) for 3 days; weakness (inability to eat or drink); dying (mental depression accompanied by hypothermia without anesthesia or sedation); rapid and abdominal breathing with pronounced effort; and severe infection. Six rats in RT group and three rats in $\alpha 2 \mathrm{M}+\mathrm{RT}$ group reached the humane and experimental endpoints exactly on day 7 after irradiation. After euthanasia by injection of pentobarbital $(1 \%, 120 \mathrm{mg} / \mathrm{kg})$, the observation time was 5-10 min to make sure animal died under fearless and painless condition. If no observation of cardiac and respiratory arrest over $10 \mathrm{~min}$, an overdose of the drug would be given.

Histological staining and quantitative bone histomorphometry. Mandible bone, tongue and buccal mucosa tissues were collected from rats and immediately immersed in $4 \%$ formaldehyde at room temperature for $24 \mathrm{~h}$. Tongue and buccal mucosa tissues were embedded into paraffin wax through dehydration and wax soaking. In addition, all bone samples were subjected to decalcification. Briefly, mandibular bone tissues were transferred from $4 \%$ paraformaldehyde into the decalcifying solution (cat. no. G1105; Servicebio) and sealed at $25-30^{\circ} \mathrm{C}$, and the solution was replaced every three days until the bone softened. All tissues were then sliced into $0.5 \mathrm{~mm}$ sections. Sections were then subjected to hematoxylin and eosin (H\&E) and Masson's trichrome staining. The samples were observed under a scanning electron microscope (NanoZoomer S360; Japan SLC, Inc.). The region of interest (ROI) was drawn from the first molar to the last molar, and both buccal and lingual cortices were visualized down to the nadir of the incisor root. With x200 magnification, nine high-power-field (HPF) images were randomly selected from different sections of each specimen, and empty lacunae were counted by three independent reviewers, as previously described (27). The number of fat vacuoles was manually counted in the different images and reported as the mean number per HPF image in the marrow cavity (28).

Tartrate-resistant acid phosphatase (TRAP) staining and terminal uridine deoxynucleotidyl nick end labeling (TUNEL) staining. Osteoclasts in the four groups (control group, $\alpha 2 \mathrm{M}$ 
group, RT group and $\alpha 2 \mathrm{M}+\mathrm{RT}$ group) were stained with a TRAP kit (cat. no. G1050; Servicebio) according to the manufacturers' instructions. TRAP-positive multinucleated cells containing three or more nuclei were counted as osteoclasts under a microscope (Leica DMi1; Leica Microsystems $\mathrm{GmbH}$ ). TRAP-positive osteoclasts were quantified with Image J software (version 1.8.0; National Institutes of Health), in terms of osteoclast number related to total bone surface (N. Oc/BS) (29).

Apoptotic cells in the four groups (control group, $\alpha 2 \mathrm{M}$ group, RT group and $\alpha 2 \mathrm{M}+\mathrm{RT}$ group) were quantified with a TUNEL apoptosis detection kit (cat. no. 11684817910; Roche Diagnostics) according to the manufacturers' instructions. Five images were randomly selected from each specimen, and the numbers of TUNEL-positive cells were counted in HPFs (magnification, $\mathrm{x} 400$ ). The apoptosis index (AI) was determined as follows: $\mathrm{AI}=$ (number of TUNEL-positive cells/total number of counted cells) x 100\%. Image-Pro Plus software (version 6.0, Media Cybernetics, Inc.) was used for automatic counting as previously described (30).

Immunohistochemistry of bone and soft tissues. The 0.5-mm thick embedded sections of four groups (control group, $\alpha 2 \mathrm{M}$ group, RT group and $\alpha 2 \mathrm{M}+\mathrm{RT}$ group) were dewaxed by microwave-heating at $60^{\circ} \mathrm{C}$ for $2 \mathrm{~h}$ and hydrated using graded ethanol $(100,95,90$ and $80 \%)$ at room temperature for $5 \mathrm{~min}$ each time. Antigen retrieval was completed at $98^{\circ} \mathrm{C}$ for $20 \mathrm{~min}$ followed by quenching for $20 \mathrm{~min}$. Sections were blocked with $1 \%$ bovine serum albumin (cat. no. A8010; Beijing Solarbio Science \& Technology Co., Ltd.) dissolved in double distilled $\mathrm{H}_{2} \mathrm{O}$ for $30 \mathrm{~min}$ at room temperature. The bone and tongue sections were incubated with primary antibodies against 8-OHdG (1:100; cat. no. ab26842; Abcam) whereas the buccal mucosa and tongue tissues were incubated with primary antibody against SOD2 (1:100; cat. no. 24127-1-AP; ProteinTech Group, Inc.) in a wet box at $4^{\circ} \mathrm{C}$ overnight. After washing twice in PBS for $5 \mathrm{~min}$, sections were incubated with goat anti-rabbit IgG (1:100; cat. no. GAR007; Multi Sciences Biotech, Co., Ltd.) or goat anti-mouse IgG (1:100; cat. no. GAM007; Multi Sciences Biotech, Co., Ltd.) at room temperature for $30 \mathrm{~min}$. Following incubation with DAB reagent (cat. no. DA1010; Beijing Solarbio Science \& Technology Co., Ltd.) for $10 \mathrm{~min}$ at room temperature and counterstain in haematoxylin, sections were mounted with neutral balsam (cat. no. G8590; Beijing Solarbio Science \& Technology Co., Ltd.). Images were captured using a light microscopy (Leica Microsystems $\mathrm{GmbH}$ ). The relative optical density (ROD) was calculated using Image-Pro Plus software as the ratio of the integrated optical density (IOD) to the measured area, as previously described (31).

Cell proliferation and apoptotic sensitivity of irradiated hBMMSCs. The primary hBMMSCs obtained from ScienCell Research Laboratories, Inc. (cat. no. 7500) were cultured in Mesenchymal Stem Cell Medium (cat. no. 7501; ScienCell Research Laboratories, Inc.) supplemented with $1 \%$ mesenchymal stem cell growth supplement (ScienCell Research Laboratories, Inc.), $1 \%$ penicillin/streptomycin solution (ScienCell Research Laboratories, Inc.) and 5\% fetal bovine serum (ScienCell Research Laboratories, Inc.) and placed in a humidified $5 \% \mathrm{CO}_{2}$ incubator at $37^{\circ} \mathrm{C}$. Cells were seeded in 96 -well plates at a density of $5 \times 10^{3}$ cells/well (6 duplicate wells per group) and were divided into four groups: Control group, no treatment; $\alpha 2 \mathrm{M}$ group, $0.5 \mathrm{mg} / \mathrm{ml} \alpha 2 \mathrm{M}$ pretreatment for $24 \mathrm{~h}$ with no irradiation; RT group, no $\alpha 2 \mathrm{M}$ pretreatment + irradiation with $8 \mathrm{~Gy}$; and $\alpha 2 \mathrm{M}+\mathrm{RT}$ group, $0.5 \mathrm{mg} / \mathrm{ml} \alpha 2 \mathrm{M}$ pretreatment for $24 \mathrm{~h}+$ one dose of $8 \mathrm{~Gy}$ dose irradiation (20). After cell treatment for 24, 48 and 72 h, $10 \mu \mathrm{l}$ of the Cell Counting Kit-8 solution (CCK-8; cat. no. C0038; Beyotime Institute of Biotechnology) was added to each well. After incubation for $2 \mathrm{~h}$ at $37^{\circ} \mathrm{C}\left(5 \% \mathrm{CO}_{2}\right)$, absorbance value was measured at a wavelength of $450 \mathrm{~nm}$ using a microplate reader (Thermo Fisher Scientific, Inc.).

Cell apoptosis was assessed with an Annexin V-FITC/PI apoptosis detection kit (cat. no. KGA108-1; Nanjing KeyGen Biotech Co., Ltd.) according to the manufacturers' instructions. Briefly, hBMMSCs were seeded at the density of $2 \times 10^{5}$ cells/well in 6-well plates and incubated for $24 \mathrm{~h}$, followed by $0.5 \mathrm{mg} / \mathrm{ml} \alpha 2 \mathrm{M}$ treatment $30 \mathrm{~min}$ before irradiation. Treated cells were cultured for $24 \mathrm{~h}$ and harvested. Cells were washed with cold PBS and resuspended in $100 \mu \mathrm{l}$ of Annexin V-FITC binding buffer. Next, $5 \mu \mathrm{l}$ of Annexin V-FITC and $10 \mu \mathrm{l}$ of PI Staining Solution were added to the samples and incubated for $15 \mathrm{~min}$ in the dark at room temperature. Subsequently, $400 \mu \mathrm{l}$ of $1 \mathrm{X}$ binding buffer was added, and cells were analyzed using flow cytometry (Beckman Cytomic FC500; Beckman Coulter). Data were analyzed using FlowJoTM software (v 10.6.2; BD Biosciences)..

ROS detection in irradiated hBMMSCs. The hBMMSCs were cultured in 6-well plates at a density of $2 \times 10^{5}$ cells/well in cell culture medium for $24 \mathrm{~h}$ before ROS detection. Cultured cells were divided into four groups: control group; $\alpha 2 \mathrm{M}$ group; RT group; and $\alpha 2 \mathrm{M}+\mathrm{RT}$ group). ROS detection was performed with a ROS assay kit (cat. no. S0033; Beyotime Institute of Biotechnology) according to the manufacturers' instructions. Culture medium was removed and cells were incubated with $10 \mu \mathrm{mol} / 1 \mathrm{DCFH}-\mathrm{DA}$ solution diluted in serum-free medium in the dark at $37^{\circ} \mathrm{C}$ for $20 \mathrm{~min}$. Cells were washed three times with serum-free medium to remove excess dye. ROS intensity was observed through inverted fluorescence microscope (Olympus IX73; Olympus Soft Imaging Solutions GmbH).

ROS level was also detected by flow cytometry. At $24 \mathrm{~h}$ after IR, hBMMSCs were harvested and washed three times with PBS. DCFH-DA (cat. no. S0033; Beyotime Institute of Biotechnology) was added to each group at a final concentration of $10 \mu \mathrm{mol} / 1$ and incubated for $20 \mathrm{~min}$ at $37^{\circ} \mathrm{C}$. Finally, the samples were washed and assessed using flow cytometer (BD FACSCanto II; BD Biosciences) and data were analyzed using FlowJo ${ }^{\mathrm{TM}}$ software (version 10.6.2; BD Biosciences).

Western blotting analysis of Akt, HO-1 and SOD2 expression. The expression of Akt, heme oxygenase-1 (HO-1), and SOD2 proteins was detected by western blotting. Briefly, cells were lysed using RIPA lysis buffer (cat. no. P0013B; Beyotime Institute of Biotechnology) for $15 \mathrm{~min}$ on ice and centrifuged at $12,000 \mathrm{rpm}$ for $15 \mathrm{~min}$ at $4^{\circ} \mathrm{C}$. Protein concentration was measured using a BCA assay kit (cat. no. 23225; Thermo Fisher Scientific, Inc.). Proteins $(50 \mu \mathrm{g})$ were separated by $10 \%$ SDS-PAGE and transferred onto PVDF membranes. 
A
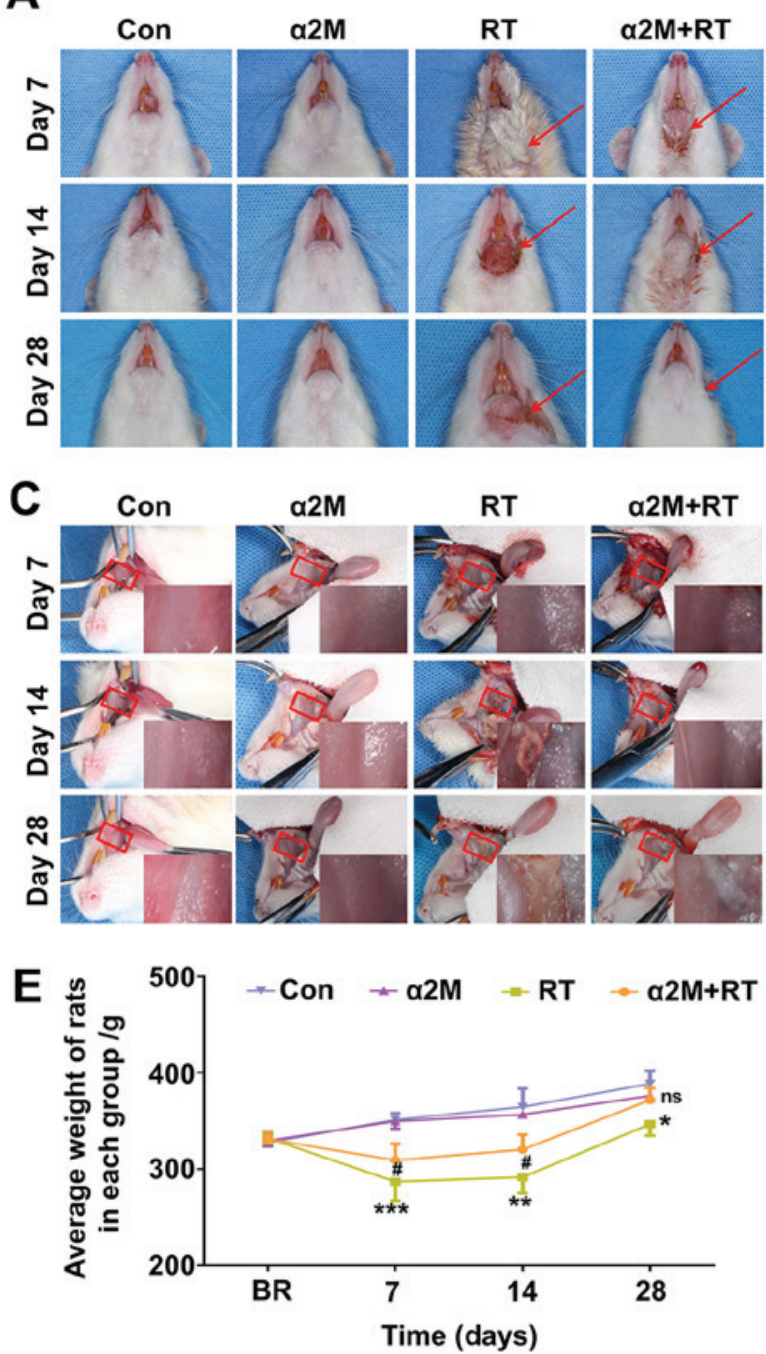

B
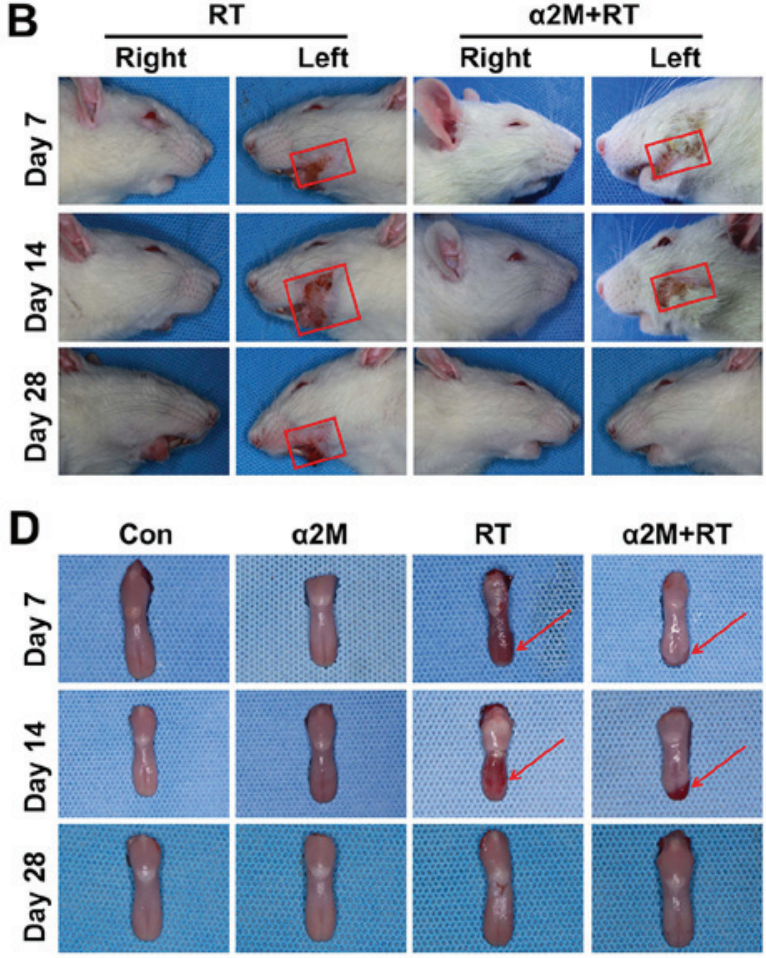

a2M

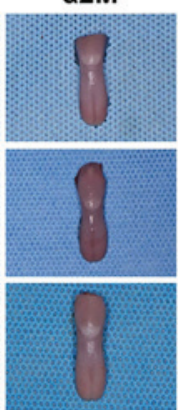

RT

$\alpha 2 M+R T$
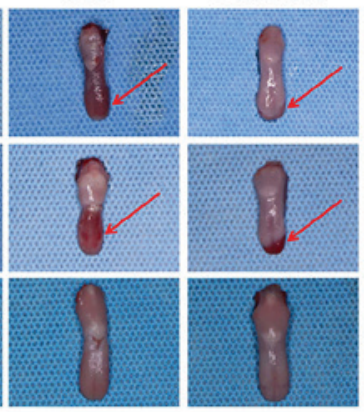

$\mathbf{F}$

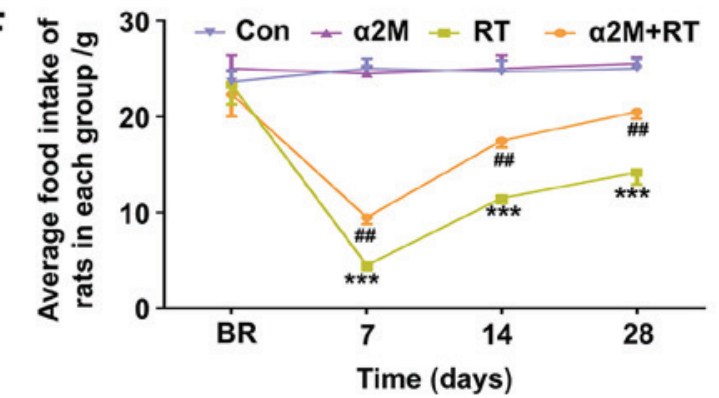

Figure 1. Radiation-induced injury and clinical symptoms and quantitation of body weight and food intake in rats. (A) RT group showed serious symptoms, including drooling, alopecia, ulceration, exudation and superficial incrustation in the irradiated area at the early stage of osteoradionecrosis. (B) $\alpha 2 \mathrm{M}+\mathrm{RT}$ group exhibited mild damage and low levels of alopecia. Red arrows in Fig. 1A and the rectangles in Fig. 1B indicate areas affected by alopecia. (C and D) Signs of irradiation are red and swollen tongue with erosive lesions and atrophied mucosa in the RT group, whereas conditions of the mucosa and tongue were substantially better in the rats in the $\alpha 2 \mathrm{M}+\mathrm{RT}$ group compared with rats in the RT group. Red arrows in Fig. 1D indicate the ulcerated areas. (E and F) Weight and food intake of rats measured weekly. ${ }^{*} \mathrm{P}<0.05,{ }^{* * *} \mathrm{P}<0.01$ and ${ }^{* * * *} \mathrm{P}<0.001$ vs. control group. ${ }^{\#} \mathrm{P}<0.05$ and ${ }^{\# \#} \mathrm{P}<0.01$ vs. RT group. $\mathrm{n}=6$ per group at $\mathrm{D} 7, \mathrm{D} 14$ or D28. Con, control; D, day; ns, not significant; RT, radiotherapy; $\alpha 2 \mathrm{M}, \alpha 2$-macroglobulin.

Membranes were blocked with $5 \%$ skimmed milk at room temperature for $1 \mathrm{~h}$ and were incubated with primary antibodies presented in Table SII at $4^{\circ} \mathrm{C}$ overnight. Membranes were washed twice with TBST (cat. no. T1085; Beijing Solarbio Science \& Technology Co., Ltd.) for $5 \mathrm{~min}$ and were incubated with secondary antibodies presented in Table SII at room temperature for $2 \mathrm{~h}$. Bands were detected with Immobilon western electrochemiluminescence HRO substrate (cat. no. P36599, Millipore) using a chemiluminescence equipment (Bio-Rad Laboratories, Inc.). The data were analyzed via densitometry using ImageJ software (version 1.8.0; National Institutes of Health).

Statistical analysis. Data were analyzed using one-way ANOVA followed by Bonferroni post hoc test for multiple comparisons. If the collected data were not normally distributed, a Kruskal-Wallis ANOVA with ranks was used. The results were analyzed using SPSS 20.0 software (IBM Corp.), and all data with a normal distribution are presented as the means \pm standard deviation. $\mathrm{P}<0.05$ was considered to indicate a statistically significant difference.

\section{Results}

$\alpha 2 M$ alleviates alopecia and mucositis at an early stage. Within 7 days and during the recovery phase, all IR rats exhibited signs and symptoms of IR side effects, including alopecia (Fig. 1A and B) and inflammation of the buccal mucosa and tongue (Fig. 1C and D). In addition, as presented in Fig. 1E, $\alpha 2 \mathrm{M}$-treated rats presented a tendency to gain weight earlier and recovered faster compared with rats in the RT group on days 7 and 14 after IR $(\mathrm{P}<0.05)$. As presented in Fig. 1F, the food intake of all IR rats began to decrease suddenly after IR and reached the lowest level on day 7 after IR, before returning to normal until the end of the study period. 


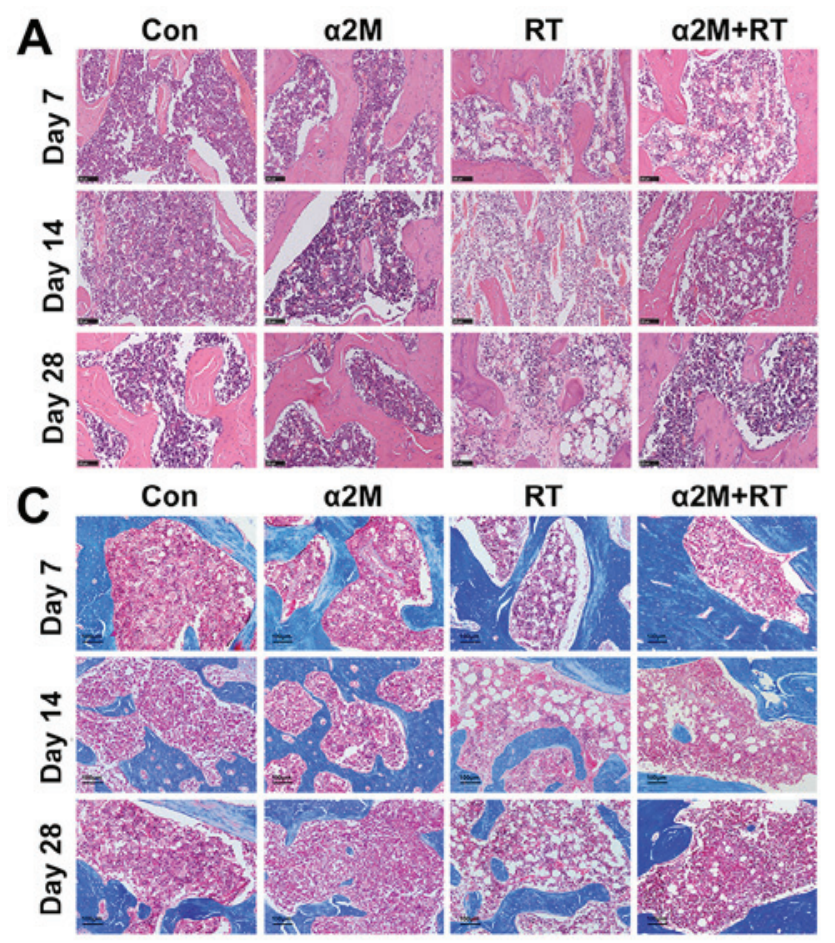

B

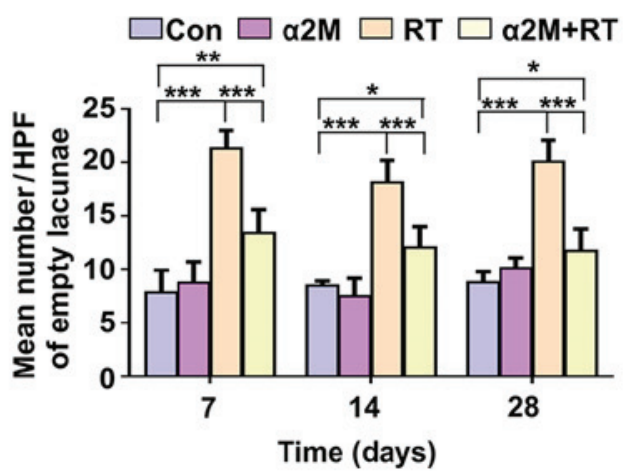

D
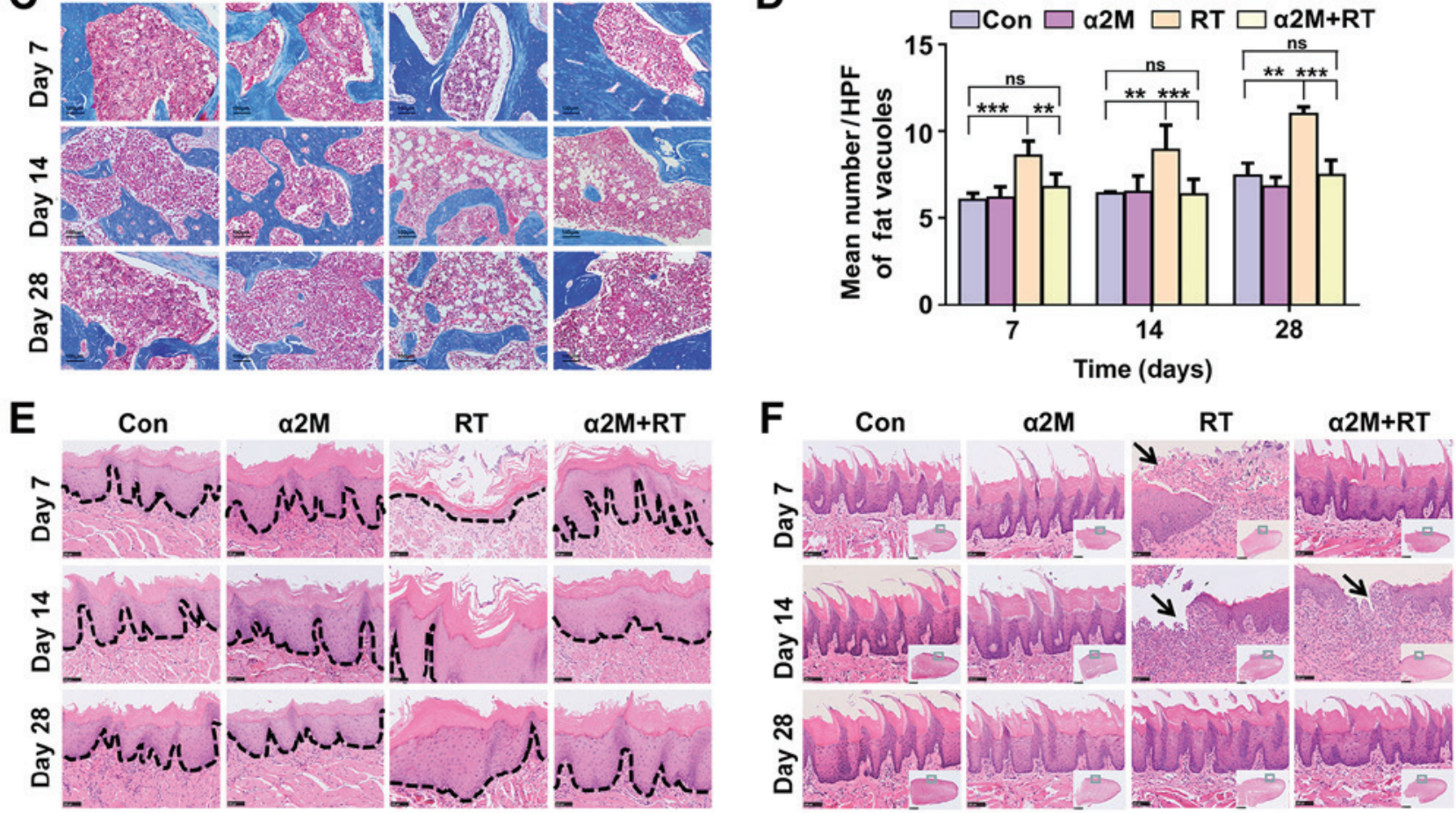

Figure 2. Pathophysiological changes associated with osteoradionecrosis in the jaws of mice in the four groups. (A) Haematoxylin and eosin staining. RT group showed significant increase in cell loss and vessel injury at each time point compared with $\alpha 2 \mathrm{M}+\mathrm{RT}$ group (scale bar, $100 \mu \mathrm{m}$ ). (B) Empty lacunae were observed in HPFs in all groups. (C) Masson's trichrome staining. $\alpha 2 \mathrm{M}+\mathrm{RT}$ group exhibited fewer fat vacuoles compared with RT group, but more than in the control group (scale bar, $100 \mu \mathrm{m}$ ). (D) Fat vacuoles were evaluated in HPFs in all groups. Pathological changes were more serious in the RT group than in the $\alpha 2 \mathrm{M}+\mathrm{RT}$ group at each time point. (E and F) RT group showed serious injuries with more regions of ulceration and erosion in the mucosa (E, scale bar, $2.5 \mathrm{~mm}$ ) and tongue (F, scale bar, $100 \mu \mathrm{m})$. Dotted lines indicate the basement membrane and black arrows indicate the ulcerated area. (B) ${ }^{* * * *} \mathrm{P}<0.001 \mathrm{vs}$. control group; ${ }^{* * *} \mathrm{P}<0.001$ vs. RT group; (D) ${ }^{* * *} \mathrm{P}<0.001$ vs. control group; ${ }^{* *} \mathrm{P}<0.01$ vs. RT group. Con, control; D, day; HFP, high-power-field; ns, not significant; RT, radiotherapy; $\alpha 2 \mathrm{M}, \alpha 2$-macroglobulin.

$\alpha 2 M$ protect against IR-induced pathophysiological changes induced in bone and soft tissues. Compared with the control group, the cell loss and vascular obstruction in bone marrow was observed in the pathological sections from the RT group. However, compared with the RT group, the $\alpha 2 \mathrm{M}+\mathrm{RT}$ group presented a decreased cell loss and vascular obstruction following IR (Fig. 2A). The number of empty bone lacunae in the RT group was significantly increased compared with the control group; however, the $\alpha 2 \mathrm{M}+\mathrm{RT}$ group showed lower bone cell death within 28 days compared with the RT group (Fig. 2B). Results from Masson's trichrome staining demonstrated no fibrosis in the bone marrow cavity in the IR groups until day 28 (Fig. 2C). In particular, a 1.5-fold increase in fat vacuoles was observed in the marrow cavity of the RT group compared with the control group (Fig. 2D). Mucosal inflammation and ulcers were observed in the IR rats at the early stage but were significantly decreased in the $\alpha 2 \mathrm{M}+\mathrm{RT}$ group compared with the RT group in the buccal mucosa (Fig. 2E) and lingual mucosa (Fig. 2F).

$\alpha 2 M$ inhibits osteoclasts activity and apoptosis of cells in the bone tissue. As presented in Fig. 3A and B, a significant increase in the number of TRAP-positive multinucleated cells was observed in the RT group compared with the control group on days 7 and 14 following IR $(\mathrm{P}<0.05)$. In addition, the results from the TUNEL assay demonstrated a significant increase in the percentage of TUNEL-positive cells in the RT group compared with the control group on days 7 and 14 after IR (Fig. 3C and D; P<0.05).

SOD2 and 8-OHdG levels in bone and soft tissues. Pretreatment with $\alpha 2 \mathrm{M}$ significantly inhibited the IR-induced 

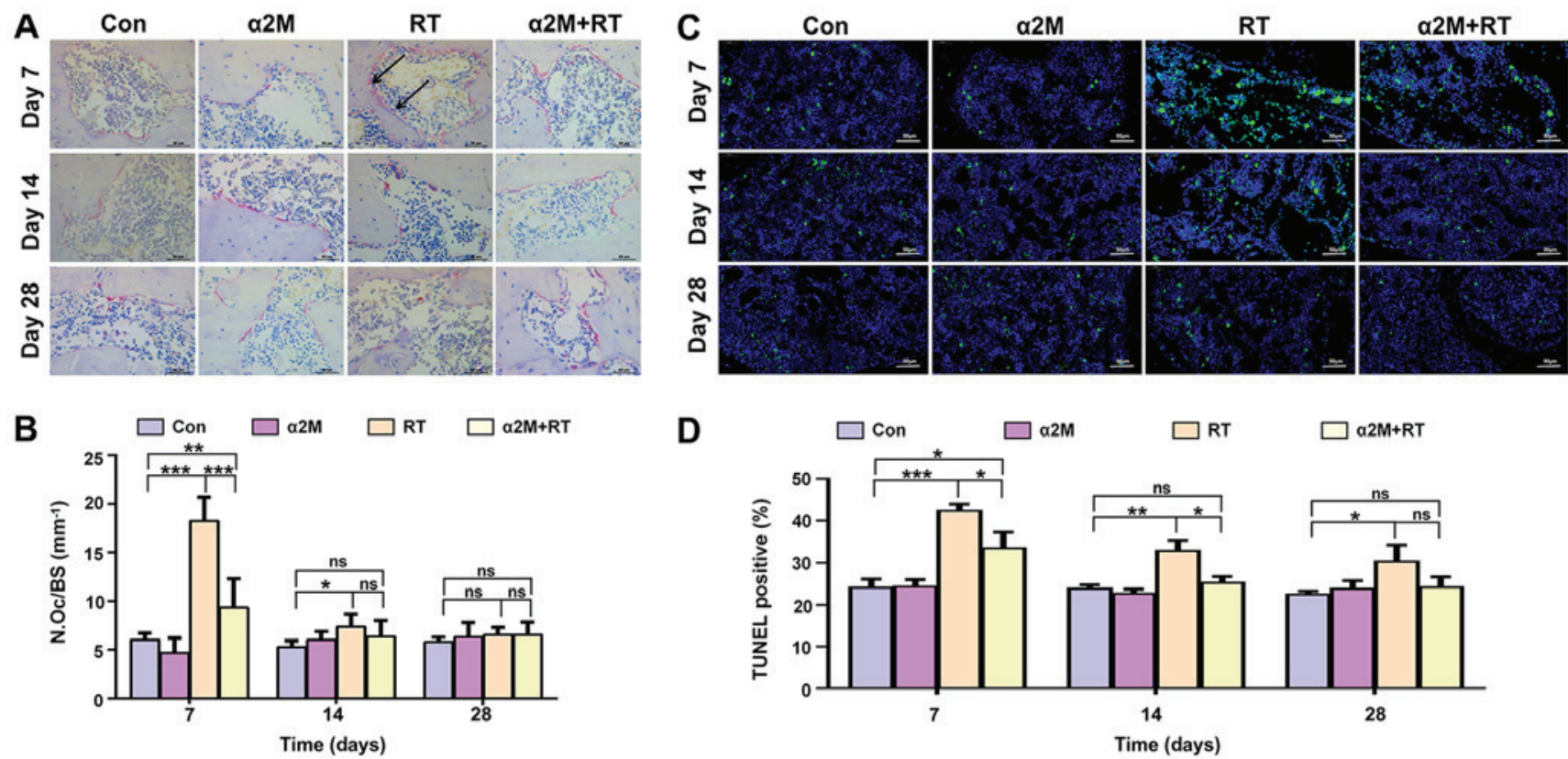

Figure 3. $\alpha 2 \mathrm{M}$ altered osteoclast activity and reduced the apoptosis rate in hBMMSCs after irradiation. (A and B) Osteoclast activity was evaluated using TRAP staining. TRAP-positive cells (osteoclasts) are stained in red. Black arrows indicate osteoclasts (scale bar, $50 \mu \mathrm{m})$. (C and D) Cell apoptosis was examined using TUNEL staining. Cells were stained using a TUNEL assay kit (green) and counterstained with DAPI (blue). Data represent the means \pm standard deviation of three independent experiments. Scale bar, $50 \mu \mathrm{m} .{ }^{*} \mathrm{P}<0.05$ and ${ }^{* * *} \mathrm{P}<0.001$ vs. control group or RT group. Con, control; D, day; HFP, high-power-field; ns, not significant; RT, radiotherapy; $\alpha 2 \mathrm{M}, \alpha 2$-macroglobulin.

increase in $8-\mathrm{OHdG}$ level $(\mathrm{P}<0.05$; Fig. 4A-D). Furthermore, following pretreatment with $\alpha 2 \mathrm{M}$, SOD2 expression was significantly increased in both the mucosa and tongue, as presented in Fig. 4E-H $(\mathrm{P}<0.05)$.

$\alpha 2 M$ reduced the apoptosis rate, improves the antioxidant capacity and increases Akt phosphorylation in IR-treated hBMMSCs. Four groups of cells were incubated in 6-well plates for $24 \mathrm{~h}$ after IR (Fig. 5A). IR-treated hBMMSCs had a lower proliferation rates than cells in the control group at 48 and $72 \mathrm{~h}(\mathrm{P}<0.001)$. However, $\alpha 2 \mathrm{M}$ pretreatment resulted in a higher proliferation rate compared with the RT group $(\mathrm{P}<0.01$; Fig. 5B). In addition, significantly increased apoptosis rate was observed in the RT group compared with the control group $(\mathrm{P}<0.01)$, and pretreatment with $\alpha 2 \mathrm{M}$ prior to IR decreased the apoptosis rate $(\mathrm{P}<0.05$; Fig. $5 \mathrm{C}$ and $\mathrm{D})$. Significant decrease in ROS levels were detected following IR in the $\alpha 2 \mathrm{M}$-treated group compared the RT group $(\mathrm{P}<0.05$; Fig. 5E-H). Furthermore, the protective effects of $\alpha 2 \mathrm{M}$ on the Akt signaling pathway were observed in the IR-treated hBMMSCs using Western blotting. Increased expression of SOD2 and HO-1 was observed in groups pretreated with $\alpha 2 \mathrm{M}$ (Fig. 5I and J).

\section{Discussion}

Numerous studies have reported some changes in the rat mandible 3 months following IR $(32,33)$. Other studies demonstrated changes in the soft tissues within two weeks after IR (34-36). However, the sequential changes observed in bone and soft tissues at the early stage after IR remain unclear. Furthermore, ORN is a disease that causes both bone and soft tissue injuries. To the best of our knowledge, the present study was the first to use a rat ORN model to investigate the early stage of ORN in bone and soft tissues.

As previously reported, IR with 30 Gy represents an ideal dose to induce a significant change in bone injury in rats $(25,26)$. However, based on a previous study that applied graded doses of 2, 4, 8 and $12 \mathrm{~Gy}$, the 8 Gy IR dose should be used to induce hBMMSC injury in vitro (20).

In the present study, cells in the marrow cavity were largely lost, vascular injury was significantly expanded and more fat vacuoles were present in the RT group compared with the control group. Conversely, the $\alpha 2 \mathrm{M}+\mathrm{RT}$ group presented resistance to IR-induced damage. As previously described by $\mathrm{Xu}$ et al (10), irreversible damage to the blood vessels caused by radiation serves a crucial role in the development of ORN. Bléry et al (25) reported an increase in the number of fat vacuoles in mandibular bone marrow following IR. In the present study, serious soft tissue injury was observed in the RT group, which was inhibited by $\alpha 2 \mathrm{M}$ treatment, specifically by reducing ulceration and erosion. These findings were consistent with those from previous studies $(18,19)$, and suggested that the potent effect of $\alpha 2 \mathrm{M}$ may be due to its ability to decrease the IR-induced toxicity in the bone and the soft tissue.

Osteocytes serve an essential role in bone reconstruction and metabolism (37). The number of osteocytes undergoing cell death is commonly calculated by counting empty lacunae during histological observations (38). IR induces bone loss and increases osteoclast numbers and activity $(39,40)$. In the present study, the number of empty lacunae increased after IR, and IR increased the activity of osteoclasts within the first week, which was consistent with previous in vivo studies describing significant increase in the number and activity of osteoclasts within the first three days after irradiation $(41,42)$. However, after the first week, the number of osteoclasts decreased in 
A

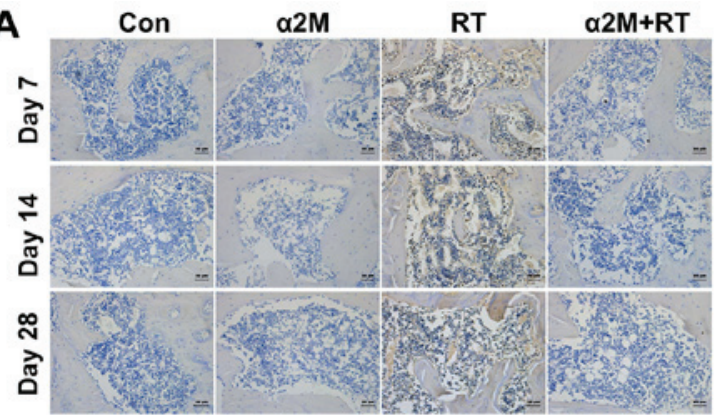

B

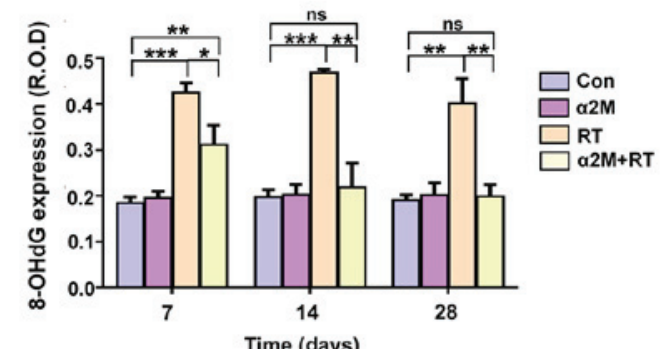

E

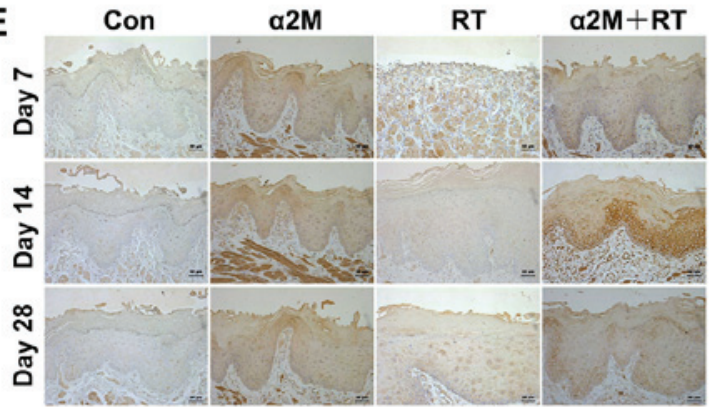

$\mathbf{F}$

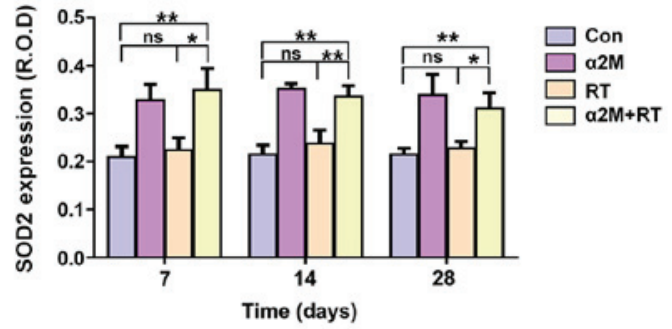

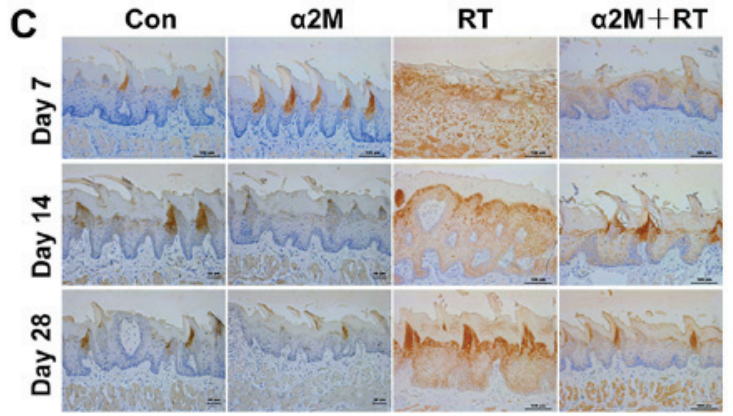

D
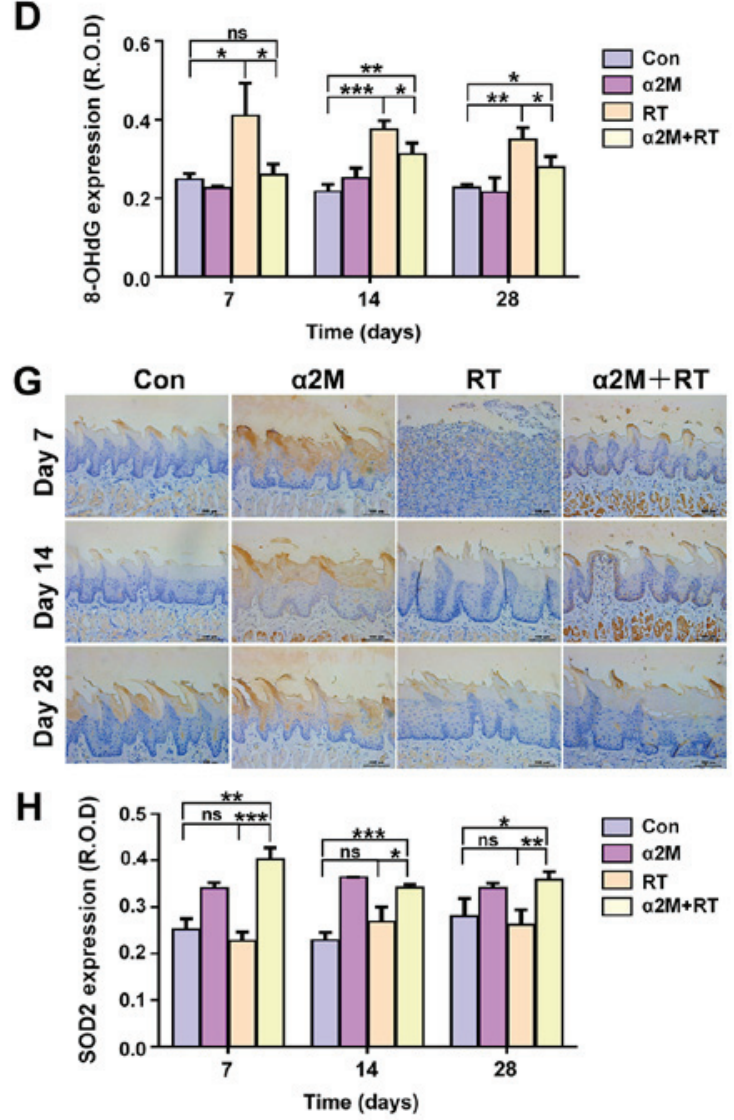

Figure 4. $\alpha 2 \mathrm{M}$ increased SOD2 expression and decreased 8-OHdG level in bone and soft tissues after irradiation. (A and B) Level of 8-OHdG in bone from the $\alpha 2 \mathrm{M}+\mathrm{RT}$ group was lower than in the RT group. Scale bar, $100 \mu \mathrm{m}$. (C and D) Levels of $8-\mathrm{OHdG}$ in the tongue tissue after IR was lower in the $\alpha 2 \mathrm{M}+\mathrm{RT}$ group than in the RT group. Scale bar, $100 \mu \mathrm{m}$. (E and F) SOD2 was expressed at higher level in the mucosa of the $\alpha 2 \mathrm{M}+\mathrm{RT}$ group than in the RT group. Scale bar, $100 \mu \mathrm{m}$. (G and H) SOD2 was expressed at a higher level in the tongue tissue after IR in the $\alpha 2 \mathrm{M}+\mathrm{RT}$ group than the RT group. Scale bar, $100 \mu \mathrm{m}$. ${ }^{*} \mathrm{P}<0.05,{ }^{* *} \mathrm{P}<0.01$ and ${ }^{* * *} \mathrm{P}<0.001$ vs. control group or RT group. Con, control; D, day; HFP, high-power-field; ns, not significant; RT, radiotherapy; $\alpha 2 \mathrm{M}$, a2-macroglobulin; 8-OHdG, 8-hydroxy-2'-deoxyguanosine; ROD, relative optical density; SOD2, superoxide dismutase 2.

the RT group, which was consistent with a previous in vivo study reporting that the cell number was decreased after 10 days (43). Because bone remodeling involves a balance between osteoclast resorption and osteoblasts activation, the findings from the present study suggested that the IR-induced disruption of this balance may contribute to the development of ORN. However, $\alpha 2 \mathrm{M}$ treatment had a significant inhibitory effect on the number of TRAP-positive osteoclasts.

ROS levels are indicators of the degree of oxidative stress (44). The biomarker $8-\mathrm{OHdG}$ was first reported by Kasai et al (45) in 1984 and is now commonly used as a sensitive indicator of oxidative stress-induced DNA damage (46). Furthermore, SOD2, which is a well-known enzyme located in the mitochondria, serves anti-apoptotic role by directly decreasing cellular ROS levels (47). $\alpha 2 \mathrm{M}$ was previously reported to inhibit ROS production by increasing SOD2 activity and to reduce oxidative stress-induced DNA damage, confirming its protective effect on radiation-induced injury in liver tissue (48). The present study aimed therefore to determine whether the radioprotective effect of $\alpha 2 \mathrm{M}$ could be associated with an antioxidant activity. The results reported increased ROS and 8-OHdG levels following IR, which was reversed after treatment with $\alpha 2 \mathrm{M}$. Furthermore, results from western blotting demonstrated an increased expression of SOD2 and HO-1 following $\alpha 2 \mathrm{M}$ treatment, suggesting that $\alpha 2 \mathrm{M}$ may possess some antioxidative effects. In addition, $\alpha 2 \mathrm{M}$ stimulated Akt activation, which is known to be activated by oxidative stress $(49,50)$.

The present study presented some promising results, which suggested the potential use of $\alpha 2 \mathrm{M}$ prophylactically 
A

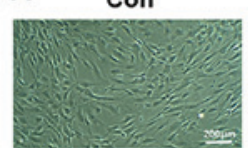

RT

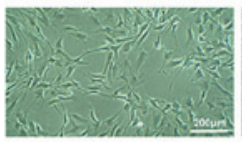

E

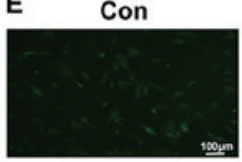

RT
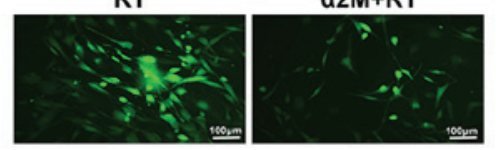

B

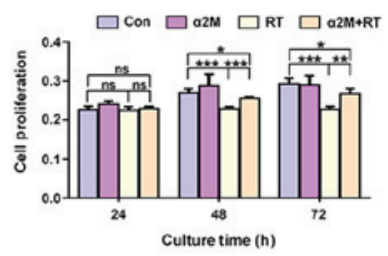

F

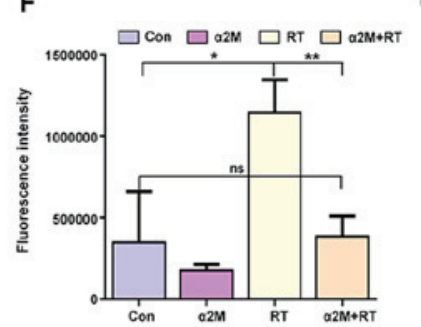

C

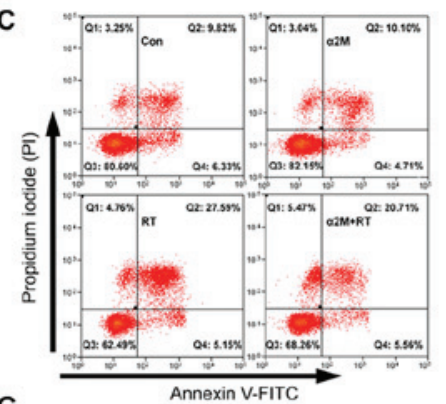

G

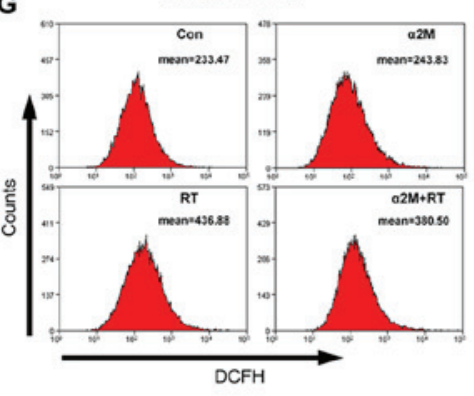

D

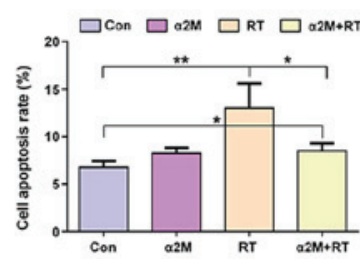

H
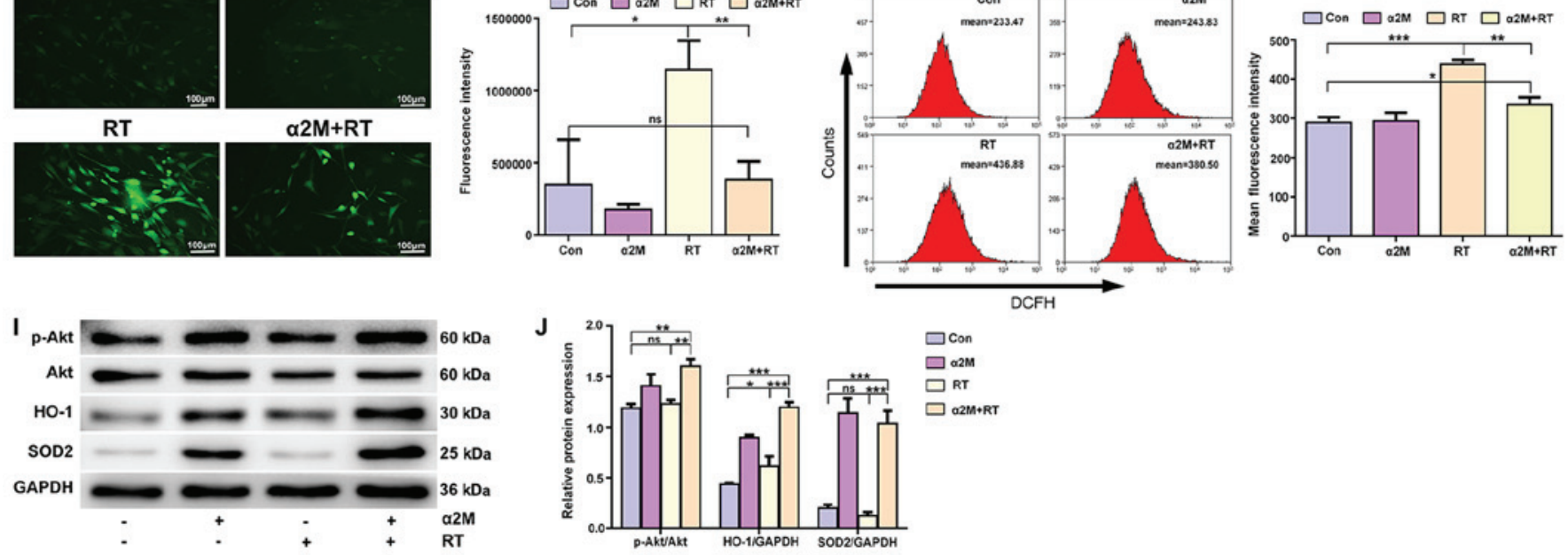

Figure 5. $\alpha 2 \mathrm{M}$ reduced the apoptosis rate, improved the antioxidant capacity and upregulated Akt phosphorylation in the IR-treated hBMMSCs. (A) Different groups of hBMMSCs were evaluated $24 \mathrm{~h}$ after IR. Scale bar, $200 \mu \mathrm{m}$. (B) CCK-8 assay was used to detect the effects of IR on hBMMSC proliferation 24,48 and $72 \mathrm{~h}$ after IR. (C and D) $\alpha 2 \mathrm{M}$ decreased the apoptosis rate in hBMMSCs $24 \mathrm{~h}$ after IR. Apoptotic rate was calculated by adding the Q2 and Q4 percentages (Q2, Annexin V and PI-positive cells; Q4, Annexin V-positive and PI-negative cells). (E and F) $\alpha 2 \mathrm{M}$ decreased ROS level in the $\alpha 2 \mathrm{M}+\mathrm{RT}$ group detected by fluorescent microscopy (E, scale bar, $100 \mu \mathrm{m}$ ) followed by statistical analysis. (G and H) $\alpha 2 \mathrm{M}$ decreased ROS level in the $\alpha 2 \mathrm{M}+\mathrm{RT}$ group detected by flow cytometry followed by a statistical analysis. (I and J) Western blotting used to detect the effect of $\alpha 2 \mathrm{M}$ on p-Akt, Akt, HO-1 and SOD2 expression in hBMMSCs $24 \mathrm{~h}$ after IR. ${ }^{*} \mathrm{P}<0.05,{ }^{* *} \mathrm{P}<0.01$ and ${ }^{* * *} \mathrm{P}<0.001$ vs. control group or RT group. DCFH, dichloro-dihydro-fluorescein; HO-1, heme oxygenase-1; p, phosphorylated; PI, propidium iodide; IR, irradiation; Con, control; D, day; HFP, high-power-field; ns, not significant; RT, radiotherapy; $\alpha 2 \mathrm{M}$, a2-macroglobulin; 8-OHdG, 8-hydroxy-2'-deoxyguanosine; ROD, relative optical density; SOD2, superoxide dismutase 2.

in clinical trials. The radioprotective effect of $\alpha 2 \mathrm{M}$ has been demonstrated by pathological alteration of rat jaw bones in the early stage of irradiation, and not only physical signs of hard and soft tissues alteration were attenuated, but the pathological changes in irradiation jaw bone were also alleviated.

This study presented some limitations. Firstly, it was not clarified how $\alpha 2 \mathrm{M}$ could regulate SOD2 expression, and further investigation is required. Regarding the radiation-induced impairment of oral epithelial cell proliferation and cell production, further investigation about the underlying mechanism of $\alpha 2 \mathrm{M}$ on irradiated soft tissue is required. Secondly, no in vitro experiments on the effect of $\alpha 2 \mathrm{M}$ on the apoptosis rate, antioxidant capacity and Akt pathway in oral epithelial cells was performed. Further in vivo experiments will explore the underlying mechanism of $\alpha 2 \mathrm{M}$ in order to determine whether SOD2 expression was affected by gene knockout or Akt overexpression. In addition, the duration and time points of $\alpha 2 \mathrm{M}$ management in patients must be further evaluated in order to determine its effectiveness.

The association between the early stage development of ORN and oxidative damage remains unclear. Our previous study discussed the radioprotective effect of $\alpha 2 \mathrm{M}$ on an animal model of jaw osteonecrosis established by fraction dose irradiation (24). In the present study, a modified rat model of osteoradionecrosis with shorter experimental period, which in the early stage of osteoradionecrosis of the jaw (ORNJ), was successfully established by a single 30 Gy dose of radiation. The present study demonstrated that ORN was associated with oxidative damage, and that $\alpha 2 \mathrm{M}$ may upregulate the activity of the antioxidant enzymes SOD2 and HO-1, leading to decreased levels of ROS and 8-OHdG. Furthermore, the expression of p-Akt in hBMMSCs was elevated following $\alpha 2 \mathrm{M}$ administration, which indicated that Akt phosphorylation may serve a role in $\alpha 2 \mathrm{M}$ effect against radiation-induced mandibular bone damage. The present study not only focused on the physical signs and pathological changes of irradiated bone tissues, but also on radiation-induced responses in soft tissues, at the early stage of ORN rat model. Based on these results, this study demonstrated that $\alpha 2 \mathrm{M}$ may protect rats from IR-induced injury by improving the endogenous antioxidant system and inhibiting the oxidative damage.

In summary, the present study was the first to demonstrate that $\alpha 2 \mathrm{M}$ may exert a radioprotective effect in early-stage ORN. The results from this study suggested that $\alpha 2 \mathrm{M}$ may represent a novel radioprotective and therapeutic agent for ORN in patients with cancer. In addition, oxidative damage observed during early-stage ORN provides a new target for preclinical studies. 


\section{Acknowledgements}

Not applicable.

\section{Funding}

This study was supported by the Natural Science Foundation of Guangdong Province (grant no. 2015A030313064), the Science and Technology Planning Project of Guangdong Province (grant no. 2017A010105027) and the Science and Technology Planning Project of Guangdong Province (grant no. 2014A020212167).

\section{Availability of data and materials}

The datasets used and analyzed during the current study are available from the corresponding author on reasonable request.

\section{Authors' contributions}

$\mathrm{JL}$ and PY conceived, planned and carried out the in vivo and in vitro experiments, respectively. JL drafted the manuscript. XK, XC and SF contributed to the study concepts and design, and critically revised the manuscript for important intellectual content. PY, WZ, YG, LQ and ZL participated in the experiments, data acquisition, quality control of the data and manuscript review. YS and XX performed the statistical analysis and scientific discussion. JM revised the manuscript. All the authors agree to be accountable for all aspects of the work. All authors read and approved the final manuscript.

\section{Ethics approval and consent to participate}

The animal experiments were approved by the Institutional Animal Care and Use Committee of Sun Yat-sen University (approval no. IACUC-DB-16-1107) and conducted in accordance with the guidelines published in the Guide for the Care and Use of Laboratory Animals (8th Edition).

\section{Patient consent for publication}

Not applicable.

\section{Competing interests}

The authors declare that they have no competing interests.

\section{References}

1. Sciubba JJ and Goldenberg D: Oral complications of radiotherapy. Lancet Oncol 7: 175-183, 2006.

2. ChrcanovicBR,ReherP,Sousa AA andHarrisM:Osteoradionecrosis of the jaws - a current overview - part 1: Physiopathology and risk and predisposing factors. Oral Maxillofac Surg 14: 3-16, 2010.

3. McGowan K, Ivanovski S and Acton C: Osteonecrosis of the jaws: A 14-year retrospective survey of hospital admissions. Aust Dent J 63: 202-207, 2018.

4. Chronopoulos A, Zarra T, Ehrenfeld M and Otto S: Osteoradionecrosis of the jaws: Definition, epidemiology, staging and clinical and radiological findings. A concise review. Int Dent J 68: 22-30, 2018.
5. Siegel RL, Miller KD and Jemal A: Cancer statistics, 2019. CA Cancer J Clin 69: 7-34, 2019.

6. Marx RE: Osteoradionecrosis: A new concept of its pathophysiology. J Oral Maxillofac Surg 41: 283-288, 1983.

7. Madrid C, Abarca M and Bouferrache K: Osteoradionecrosis: An update. Oral Oncol 46: 471-474, 2010.

8. Poort LJ, Ludlage JH, Lie N, Böckmann RA, Odekerken JC, Hoebers FJ and Kessler PA: The histological and histomorphometric changes in the mandible after radiotherapy: An animal model. J Craniomaxillofac Surg 45: 716-721, 2017.

9. Marx RE and Johnson RP: Studies in the radiobiology of osteoradionecrosis and their clinical significance. Oral Surg Oral Med Oral Pathol 64: 379-390, 1987.

10. Xu J, Zheng Z, Fang D, Gao R, Liu Y, Fan ZP, Zhang CM and Wang SL: Early-stage pathogenic sequence of jaw osteoradionecrosis in vivo. J Dent Res 91: 702-708, 2012.

11. Xu J, Zheng Z, Fang D, Gao R, Liu Y, Fan Z, Zhang C, Shi S and Wang S: Mesenchymal stromal cell-based treatment of jaw osteoradionecrosis in Swine. Cell Transplant 21: 1679-1686, 2012.

12. Caplan AI: Mesenchymal stem cells. J Orthop Res 9: 641-650, 1991.

13. Mazur L, Augustynek A, Halicka HD and Deptała A: Induction of apoptosis in bone marrow cells after treatment of mice with WR-2721 and gamma-rays: Relationship to the cell cycle. Cell Biol Toxicol 19: 13-27, 2003.

14. Cao X, Wu X, Frassica D, Yu B, Pang L, Xian L, Wan M, Lei W, Armour M, Tryggestad E, et al: Irradiation induces bone injury by damaging bone marrow microenvironment for stem cells. Proc Natl Acad Sci USA 108: 1609-1614, 2011.

15. Rehman AA, Zaman M, Zia MK, Ahsan H, Khan RH and Khan FH: Conformational behavior of alpha-2-macroglobulin: Aggregation and inhibition induced by TFE. Int J Biol Macromol 104: 539-546, 2017.

16. Chen X, Kong X, Zhang Z, Chen W, Chen J, Li H, Cao W, Ge Y and Fang S: Alpha-2-macroglobulin as a radioprotective agent: A review. Chin J Cancer Res 26: 611-621, 2014.

17. Uskoković A, Dinić S, Mihailović M, Grigorov I, Ivanović-Matić S, Bogojević D, Grdović N, Arambasić J, Vidaković M, Martinović V, et al: STAT3/NFkappaB interplay in the regulation of alpha2-macroglobulin gene expression during rat liver development and the acute phase response. IUBMB Life 59: 170-178, 2007.

18. Bogojević D, Poznanović G, Grdović N, Grigorov I, Vidaković M, Dinić $S$ and Mihailović M: Administration of rat acute-phase protein $\alpha(2)$-macroglobulin before total-body irradiation initiates cytoprotective mechanisms in the liver. Radiat Environ Biophys 50: 167-179, 2011.

19. Mirjana M, Goran P, Nevena G, Melita V, Svetlana D, Ilijana G and Desanka B: The rat acute-phase protein $\alpha 2$-macroglobulin plays a central role in amifostine-mediated radioprotection. J Radiol Prot 30: 567-583, 2010.

20. Liu Y, Cao W, Kong X, Li J, Chen X, Ge Y, Zhong W and Fang S: Protective effects of $\alpha 2$ macroglobulin on human bone marrow mesenchymal stem cells in radiation injury. Mol Med Rep 18: 4219-4228, 2018

21. Moroni L and Fornasari PM: Human mesenchymal stem cells: A bank perspective on the isolation, characterization and potential of alternative sources for the regeneration of musculoskeletal tissues. J Cell Physiol 228: 680-687, 2013.

22. Baker N, Boyette LB and Tuan RS: Characterization of bone marrow-derived mesenchymal stem cells in aging. Bone 70: $37-47,2015$

23. Wang Y, Zhu G, Wang J and Chen J: Irradiation alters the differentiation potential of bone marrow mesenchymal stem cells. Mol Med Rep 13: 213-223, 2016

24. Li J, Kong XB, Chen XY, Zhong WZ, Chen JY, Liu Y, Yin P and Fang SL: Protective role of $\alpha 2$-macroglobulin against jaw osteoradionecrosis in a preclinical rat model. J Oral Pathol Med 48: 166-173, 2019.

25. Bléry P, Espitalier F, Hays A, Crauste E, Demarquay C, Pilet P, Sourice S, Guicheux J,Malard O,Benderitter M, et al: Development of mandibular osteoradionecrosis in rats: Importance of dental extraction. J Craniomaxillofac Surg 43: 1829-1836, 2015.

26. Cohen M, Nishimura I, Tamplen M, Hokugo A, Beumer J, Steinberg ML, Suh JD, Abemayor E and Nabili V: Animal model of radiogenic bone damage to study mandibular osteoradionecrosis. Am J Otolaryngol 32: 291-300, 2011.

27. Tchanque-Fossuo CN, Monson LA, Farberg AS, Donneys A, Zehtabzadeh AJ, Razdolsky ER and Buchman SR: Dose-response effect of human equivalent radiation in the murine mandible: Part I. A histomorphometric assessment. Plast Reconstr Surg 128: 114-121, 2011. 
28. Spencer M, Yang L, Adu A, Finlin BS, Zhu B, Shipp LR, Rasouli N, Peterson CA and Kern PA: Pioglitazone treatment reduces adipose tissue inflammation through reduction of mast cell and macrophage number and by improving vascularity. PLoS One 9: e102190, 2014.

29. Wang L, Liu S, Zhao Y, Liu D, Liu Y, Chen C, Karray S, ShiS and Jin Y: Osteoblast-induced osteoclast apoptosis by fas ligand/FAS pathway is required for maintenance of bone mass. Cell Death Differ 22: 1654-1664, 2015.

30. Tan H, Qi J, Fan BY, Zhang J, Su FF and Wang HT: MicroRNA-24-3p attenuates myocardial ischemia/reperfusion injury by suppressing RIPK 1 expression in mice. Cell Physiol Biochem 51: 46-62, 2018

31. Liu L, Jin X, Hu CF, Li R, Zhou Z and Shen CX: Exosomes derived from mesenchymal stem cells rescue myocardial ischaemia/reperfusion injury by inducing cardiomyocyte autophagy via AMPK and Akt pathways. Cell Physiol Biochem 43: 52-68, 2017.

32. Niehoff P, Springer IN, Acil Y, Lange A, Marget M, Roldán JC, Köppe K, Warnke PH, Kimmig B and Wiltfang J: HDR brachytherapy irradiation of the jaw - as a new experimental model of radiogenic bone damage. J Craniomaxillofac Surg 36: 203-209, 2008.

33. Monson LA, Jing XL, Donneys A, Farberg AS and Buchman SR: Dose-response effect of human equivalent radiation in the mandible. J Craniofac Surg 24: 1593-1598, 2013.

34. Chang JW, Choi JW, Lee BH, Park JK, Shin YS, Oh YT, Noh OK and $\mathrm{Kim} \mathrm{CH}$ : Protective effects of Korean red ginseng on radiation-induced oral mucositis in a preclinical rat model. Nutr Cancer 66: 400-407, 2014.

35. Han G, Bian L, Li F, Cotrim A, Wang D, Lu J, Deng Y, Bird G, Sowers A, Mitchell JB, et al: Preventive and therapeutic effects of Smad7 on radiation-induced oral mucositis. Nat Med 19: 421-428, 2013.

36. Maria OM, Shalaby M, Syme A, Eliopoulos N and Muanza T: Adipose mesenchymal stromal cells minimize and repair radiation-induced oral mucositis. Cytotherapy 18: 1129-1145, 2016.

37. Sapir-Koren R and Livshits G: Osteocyte control of bone remodeling: Is sclerostin a key molecular coordinator of the balanced bone resorption-formation cycles? Osteoporos Int 25: 2685-2700, 2014.

38. Zong C, Cai B, Wen X, Alam S, Chen Y, Guo Y, Liu Y and Tian L: The role of myofibroblasts in the development of osteoradionecrosis in a newly established rabbit model. J Craniomaxillofac Surg 44: 725-733, 2016

39. Willey JS, Lloyd SA, Nelson GA and Bateman TA: Ionizing radiation and none loss: Space exploration and clinical therapy applications. Clin Rev Bone Miner Metab 9: 54-62, 2011.

40. Sibonga JD: Spaceflight-induced bone loss: Is there an osteoporosis risk? Curr Osteoporos Rep 11: 92-98, 2013.
41. Willey JS, Lloyd SA, Robbins ME, Bourland JD, Smith-Sielicki H, Bowman LC, Norrdin RW and Bateman TA: Early increase in osteoclast number in mice after whole-body irradiation with $2 \mathrm{~Gy}$ X rays. Radiat Res 170: 388-392, 2008.

42. Green DE, Adler BJ, Chan ME and Rubin CT: Devastation of adult stem cell pools by irradiation precedes collapse of trabecular bone quality and quantity. J Bone Miner Res 27: 749-759, 2012.

43. Sawajiri M, Mizoe J and Tanimoto K: Changes in osteoclasts after irradiation with carbon ion particles. Radiat Environ Biophys 42: 219-223, 2003.

44. Sakuma S, Abe M, Kohda T and Fujimoto Y: Hydrogen peroxide generated by xanthine/xanthine oxidase system represses the proliferation of colorectal cancer cell line Caco-2. J Clin Biochem Nutr 56: 15-19, 2015.

45. Kasai H, Hayami H, Yamaizumi Z, SaitôH and Nishimura S: Detection and identification of mutagens and carcinogens as their adducts with guanosine derivatives. Nucleic Acids Res 12: 2127-2136, 1984

46. Valavanidis A, Vlachogianni T and Fiotakis C: 8-hydroxy-2'-deoxyguanosine (8-OHdG): A critical biomarker of oxidative stress and carcinogenesis. J Environ Sci Health Part C Environ Carcinog Ecotoxicol Rev 27: 120-139, 2009.

47. Ruiz-Perera LM, Schneider L, Windmöller BA, Müller J, Greiner JF, Kaltschmidt C and Kaltschmidt B: NF- $\kappa$ B p65 directs sex-specific neuroprotection in human neurons. Sci Rep 8: 16012, 2018.

48. Ivanov VE, Usacheva AM, Chernikov AV, Bruskov VI and Gudkov SV: Formation of long-lived reactive species of blood serum proteins induced by low-intensity irradiation of helium-neon laser and their involvement in the generation of reactive oxygen species. J Photochem Photobiol B 176: 36-43, 2017.

49. Bautista E, Vergara P and Segovia J: Iron-induced oxidative stress activates AKT and ERK1/2 and decreases Dyrk1B and PRMT1 in neuroblastoma SH-SY5Y cells. J Trace Elem Med Biol 34: 62-69, 2016

50. Lim SW, Jin L, Luo K, Jin J, Shin YJ, Hong SY and Yang CW: Klotho enhances FoxO3-mediated manganese superoxide dismutase expression by negatively regulating PI3K/AKT pathway during tacrolimus-induced oxidative stress. Cell Death Dis 8: e2972, 2017.

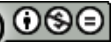

This work is licensed under a Creative Commons Attribution-NonCommercial-NoDerivatives 4.0 International (CC BY-NC-ND 4.0) License. 